\title{
Improved EDS Performance at EBSD Geometry
}

\author{
M.M. Nowell, R. Anderhalt, T. Nylese, F. Eggert, R. de Kloe, M. Schleifer, and S.I. Wright
}

EDAX Inc., 91 McKee Drive, Mahwah, NJ, 07430

The simultaneous acquisition of Energy Dispersive Spectroscopy (EDS) and Electron Backscatter Diffraction (EBSD) data has proven useful for the identification and analysis of multi-phase materials. However due to the differences between the interaction volume sizes characteristic to EDS and EBSD and to the differences between the EDS interaction volume distributions at the large specimen tilts required for EBSD pattern collection and at a typical non-tilted EDS geometry some care must be taken to accurately analyze this simultaneously collected EDS data.

An EDS quantification model, termed eZAF, which incorporates a blend of the most advanced models with recent and more precise atomic mass absorption coefficients, was used to quantify spectra from a variety of samples at EBSD geometry ( $75^{\circ}$ sample tilt in this case) and compared to results collected at $0^{\circ}$ tilt. The spectra were collected using an FEI XL-30 FEG SEM operating at $20 \mathrm{kV}$ with an incident beam current of approximately $2.5 \mathrm{nA}$, which is typical for EBSD operation, and produced EDS count rates of approximately $80-100 \mathrm{kcps}$ using a 30 $\mathrm{mm}^{2}$ Apollo XL SDD EDS detector. Multiple spectra were collected from both tilt values for 20 live seconds using a $1.6 \mu \mathrm{s}$ amp time to achieve a dead time of approximately $30 \%$. This collection time was selected as a reasonable approximation for the time necessary to collect a high-resolution, high-quality EBSD pattern to be used for phase identification, with the quantification results comparable to data with longer collection times.

Samples of Raney nickel (containing $\mathrm{Al}_{3} \mathrm{Ni}_{2}$ and $\mathrm{Al}_{3} \mathrm{Ni}$ phases), Titanium 6-4 (6\% Al, 4\% $\mathrm{V}$ by weight), Inconel 600 (72\% $\mathrm{Ni}(\mathrm{min}), 15.5 \% \mathrm{Cr}, 8 \% \mathrm{Fe}, 1.0 \% \mathrm{Mn}, 0.5 \% \mathrm{Si}, 0.5 \% \mathrm{Cu}$ by weight), and hematite ( $\mathrm{Fe} 2 \mathrm{O} 3$ with some substitution of $\mathrm{Sr}$ for $\mathrm{Fe}$ ) were polished for EBSD and used for these EDS tests. For the Raney nickel phases, spectra were collected using spot collection from the same grains at both geometries and compared. For the other samples, spectra were collected from an area rather than a spot. The root mean square deviation of the constituent elemental compositions between the tilted and averaged (except for the Raney nickel phases) non-tilted spectra were calculated, and the results shown in Table 1 . In most cases, less than $0.5 \%$ deviation is present in the tilted geometry measurements.

When the microstructural (primarily phase) and EBSD mapping sampling sizes are near or less than the spatial scale of the EDS interaction volume, it is possible that the majority of the EDS signal is generated from a different phase than the EBSD pattern as shown in Figure 1a. In this situation, the correlation between the EDS and EBSD data is inaccurate and this can hinder any phase differentiation attempts using the simultaneous data. It is possible to improve this correlation by shifting the EDS data using knowledge of the specimen geometry and EBSD step size. The use of this EDS shift to improve results is shown in Figure 1. 
References

[1] A.O. Sandborg et al., Microsc. Microanal. 8 (Suppl. 2) (2002) 1468CD.

[2] W.T. Elam et al., Radiation Physica and Chemistry, 63 (2002).

[3] M.M. Nowell and S.I. Wright, J Microsc, 213 (2004).

TABLE 1. Deviations between tilted and non-tilted measurements

\begin{tabular}{lcc}
\hline $\begin{array}{l}\text { Sample } \\
\text { Material }\end{array}$ & $\begin{array}{l}\text { Average } \\
\text { constituent compositions. }\end{array}$ \\
\hline $\mathrm{Al}_{3} \mathrm{Ni}_{2}$ & 0.294 \\
$\mathrm{Al}_{3} \mathrm{Ni}$ & 0.260 \\
$\mathrm{Ti} 6 \mathrm{Al} 4 \mathrm{~V}$ & 0.416 \\
Inconel 600 & 0.365 \\
$\mathrm{Fe}_{2} \mathrm{O}_{3}$ & 1.395 \\
\hline
\end{tabular}

(a)

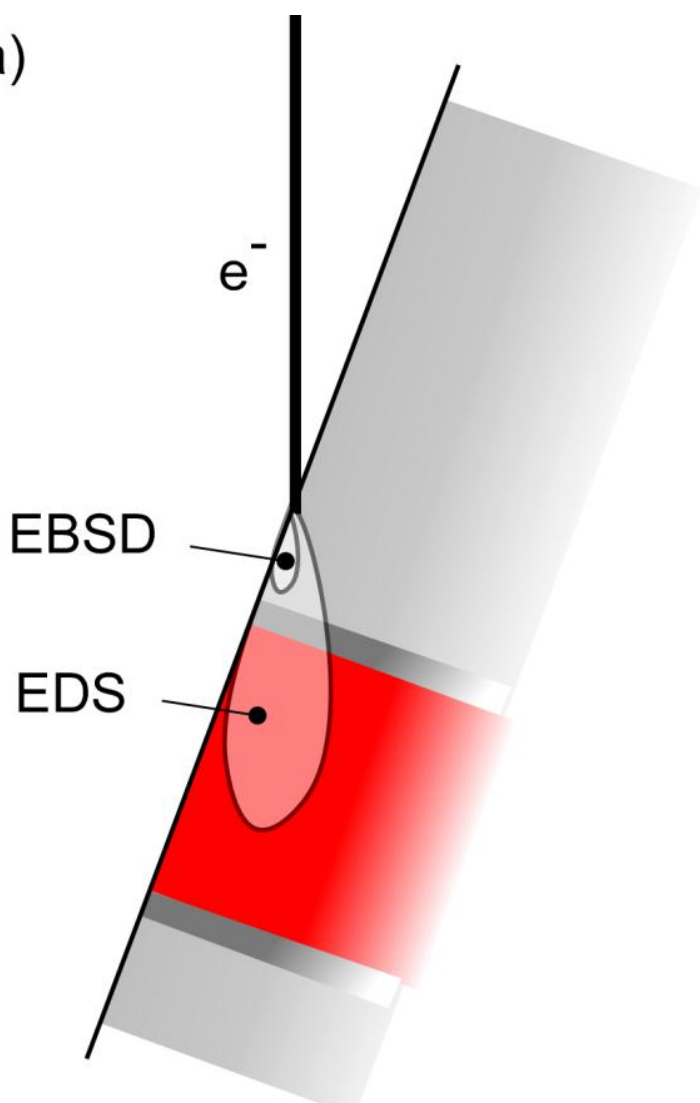

(b)

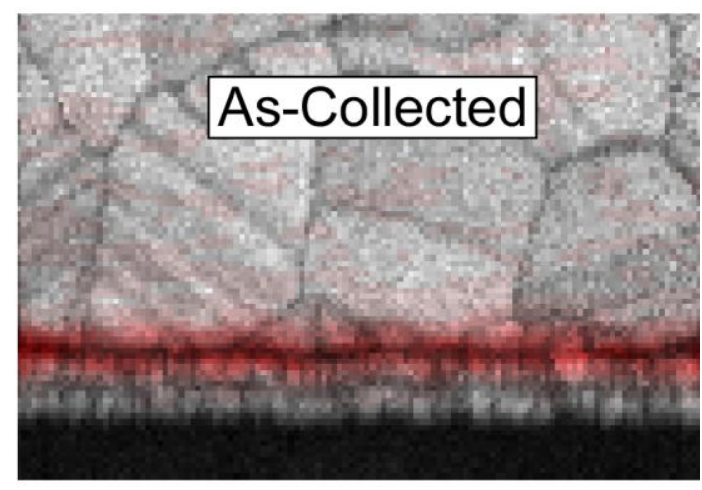

(c)

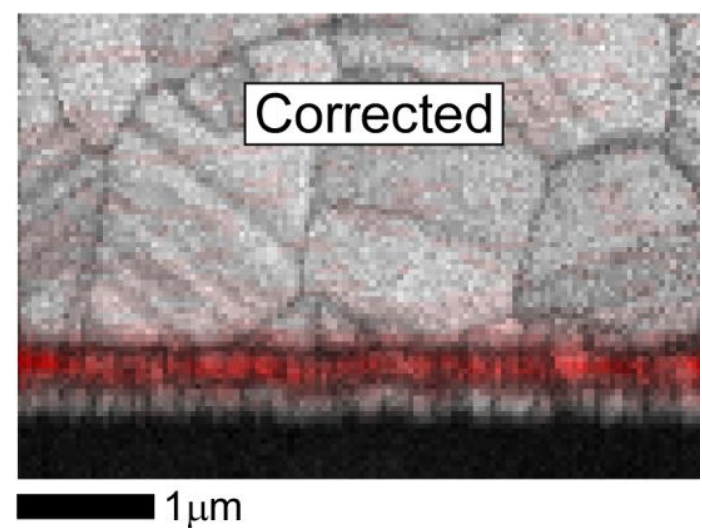

FIG. 1. A) Schematic of EBSD and EDS interaction volumes showing EBSD generated from one region and the majority of the EDS signal generated from another. As-collected (1B) and spatially corrected data (1C) from sub-micron layered sample showing improved correlation of collected EDS signal with observed microstructure. 